\title{
Patient preference and willingness to pay for transient elastography versus liver biopsy: A perspective from British Columbia
}

\author{
Victoria Y Kan BSc MHA, Vladimir Marquez Azalgara MD MSc, Jo-Ann E Ford MScN, \\ WC Peter Kwan MD, Siegfried R Erb MD, Eric M Yoshida MD MHSc
}

VY Kan, V Marquez Azalgara, JE Ford, WCP Kwan, SR Erb, EM Yoshida. Patient preference and willingness to pay for transient elastography versus liver biopsy: A perspective from British Columbia. Can J Gastroenterol Hepatol 2015;29(2):72-76.

BACKGROUND: The cost of liver biopsy (LB) is publicly funded in British Columbia, while the cost of transient elastography (FibroScan [FS], Echosens, France) is not. Consequently, there is regional variation regarding FS access and monitoring of liver disease progression. OBJECTIVE: To evaluate patient preference for FS versus LB and to assess the willingness to self-pay for FS.

METHODS: Questionnaires were distributed in clinic and via mail to LB-experienced and LB-naive patients who underwent FS at Vancouver General Hospital, Vancouver, British Columbia.

RESULTS: The overall response rate was $76 \%$. Of the 422 respondents, 205 were LB-experienced. The mean age was 53.5 years, $50.2 \%$ were male, $54.7 \%$ were Caucasian, $38.2 \%$ had hepatitis C and $26.3 \%$ had an annual household income $>\$ 75,000$. Overall, $95.4 \%$ of patients preferred FS to LB. FS was associated with greater comfort than LB, with the majority reporting no discomfort during FS $(84.1 \%$ versus $7.8 \%$ for $\mathrm{LB})$, no discomfort after $(96.2 \%$ versus $14.6 \% \mathrm{LB})$ and no feelings of anxiety after FS explanation ( $78.2 \%$ versus $12.7 \% \mathrm{LB})$. FS was also associated with greater speed, with the majority reporting short test duration ( $97.2 \%$ versus $48.3 \% \mathrm{LB}$ ) and short wait for the test result (95.5\% versus 30.2\% LB). Most (75.3\%) respondents were willing to self-pay for FS, with $26.3 \%$ willing to pay $\$ 25$ to $\$ 49$. Patients with unknown liver disease preferred LB (OR [FS preference] 0.20 [95\% CI 0.07 to 0.53$]$ ).

CONCLUSIONS: FS was the preferred method of assessing liver fibrosis among patients, with the majority willing to self-pay. To ensure consistency in access, provincial funding for FS is needed. However, LB remains the procedure of choice for individuals with an unknown diagnosis.

Key Words: Fibroscan; Liver biopsy; Patient; Preference; Transient elastography

$\mathrm{D}$ termining the appropriate treatment and management of chronic liver disease often relies on the degree of liver fibrosis. Although liver biopsy (LB) is the gold standard for liver fibrosis assessment, it is considered to be an invasive, resource-intensive and painful procedure that carries the risk of mild to severe complications (1-3). Furthermore, it is associated with several technical limitations including interobserver variability among pathologists and sampling variation (4-6).

Due to the drawbacks of LB, there has been significant focus on developing safer, noninvasive and more efficient means of evaluating liver fibrosis. Transient elastography (FibroScan [FS], Echosens, France) is one such noninvasive test that was approved for use in Canada in 2009. Since its approval, FS has been believed to be the preferred alternative to LB due to its noninvasive nature, painless and
La préférence des patients et leur disposition à payer une élastographie transitoire plutôt qu'une biopsie du foie : le point de vue de la Colombie-Britannique

HISTORIQUE : Le régime public paie le coût de la biopsie du foie (BF) en Colombie-Britannique, mais pas celui de l'élastographie transitoire (FibroScan [FS], Echosens, France). Par conséquent, on observe des variations régionales en matière d'accès au FS et de surveillance de l'évolution des hépatopathies.

OBJECTIF : Évaluer la préférence des patients envers le FS ou la BF et leur disposition à payer eux-mêmes le FS.

MÉTHODOLOGIE : Des patients qui avaient déjà subi ou non une BF et qui se soumettaient à un FS au Vancouver General Hospital, en Colombie-Britannique, ont reçu un questionnaire en clinique et par la poste.

RÉSULTATS : Le taux de réponse globale s'est élevé à $76 \%$. De ces 422 répondants, 205 avaient déjà subi une $\mathrm{BF}$. Ils avaient un âge moyen de 53,5 ans, 50,2 \% étaient de sexe masculin, 54,7\% étaient blancs, 38,2\% avaient une hépatite $\mathrm{C}$ et $26,3 \%$ avaient un revenu familial annuel de plus de 75000 \$. Dans l'ensemble, 95,4\% des patients préféraient le FS à la BF. Le FS causait moins d'inconfort que la BF, la majorité déclarant n'avoir ressenti aucun inconfort pendant le FS (84,1 \% par rapport à 7,8\% pour la $\mathrm{BF})$, aucun inconfort après le FS (96,2 \% par rapport à $14,6 \%$ pour la $\mathrm{BF}$ ) et aucun sentiment d'anxiété après l'explication sur le FS (78,2 \% par rapport à $12,7 \%$ pour la BF). Le FS était également plus rapide à effectuer, la majorité le trouvant court $(97,2 \%$ par rapport à $48,3 \% \mathrm{BF}$ ) et trouvant l'attente courte avant d'en obtenir les résultats (95,5\% par rapport à 30,2\% pour la $\mathrm{BF})$. La plupart des répondants $(75,3 \%)$ étaient disposés à payer le FS, 26,3 \% étant prêts à débourser de 25 \$ à 49 \$. Les patients dont l'hépatopathie n'était pas connue préféraient la BF (RC [préférence pour le FS] de 0,20 [95 \% IC 0,07 à 0,53]). CONCLUSIONS : Le FS était la méthode favorisée pour évaluer la fibrose hépatique chez les patients, dont la majorité était disposée à la payer. Pour garantir une uniformité d'accès, il faut assurer le financement provincial du FS. Cependant, la BF demeure l'intervention de choix pour les personnes dont on ne connaît pas le diagnostic.

Division of Gastroenterology, Vancouver General Hospital, Vancouver, British Columbia

Correspondence: Dr Eric M Yoshida, Vancouver General Hospital, Division of Gastroenterology, Diamond Health Care Centre, 5153-2775 Laurel Street,

Vancouver, British Columbia V5Z 1M9. Telephone 604-875-5371, fax 604-875-5447, e-mail eric.yoshida@vch.ca

Received for publication November 1, 2014. Accepted November 7, 2014 
LB and FS are both approved methods of fibrosis assessment in Canada; however, the cost of LB is covered under all provincial health care plans and the cost of FS is not. Quebec is the only province currently reimbursing for FS, with work in progress in British Columbia, Alberta, Ontario and Nova Scotia (16). As a result of this lack of public funding for FS, there is regional variation regarding access to FS and monitoring of liver disease progression. Specifically, FS clinics tend to be located at university hospitals and private practices rather than community-based hospitals, making physical accessibility an issue (16). Further adding to this issue of physical accessibility is the finding that the majority $(59.6 \%$ ) of Canadian specialists do not have a FS in their clinics, and $61.3 \%$ of these physicians do not have convenient access to FS whatsoever (16). Moreover, the amount patients are charged for FS can range from nil to hundreds of dollars depending on the site, thus posing financial barriers for some individuals.

To date, studies have shown FS to have high diagnostic accuracy compared with LB. Studies have also demonstrated overwhelming physician acceptance of FS as a novel, noninvasive method of assessing liver fibrosis. However, there are no data regarding the suitability of FS in terms of patient preference. Knowledge of their preference is of the utmost importance because patients are key stakeholders in the current efforts being made toward provincial reimbursement for FS. The present study, therefore, aimed to evaluate preference for FS versus LB among patients in British Columbia.

\section{METHODS}

The present study involved a survey of patients who underwent FS at Vancouver General Hospital (Vancouver, British Columbia) between March 1, 2011 and April 4, 2014. The questionnaire was distributed to patients via mail as well as in clinic over a period of three months (January 3 to April 4, 2014). Patients who underwent FS before the distribution of questionnaires in clinic (between March 1, 2011 and January 2, 2014) and had documentation of having previously undergone a LB in their clinic chart were mailed a questionnaire. Patients who underwent FS between January 3 and April 4, 2014, regardless of previous LB experience, were administered the questionnaire in clinic. The present study was approved by the Behavioural Research Ethics Board at the University of British Columbia, Vancouver, British Columbia.

The structured questionnaire assessed the following variables regarding patient experience with FS and LB (if applicable): patient discomfort during and after the test; anxiety experienced after having the test explained to them but before the test itself; perceived duration of the test; perceived duration of wait for test results; and time taken off work for testing. The questionnaire also assessed test preference, willingness to self-pay for the FS, and amount respondents were willing to pay. Brief descriptions of both tests were included in the questionnaires to mimic information that would normally be provided to patients, and to ensure patients (particularly those contacted through mail) were recalling the correct tests. For individuals who had never undergone $\mathrm{LB}$, a more thorough description of the procedure and the standard instructions usually provided to a patient before the procedure were also included in the questionnaire. Finally, the questionnaire obtained demographic information from respondents including age, sex, annual household income, ancestry and liver disease history. Response options consisted of Likert-type scale responses, categorical response options, ordinal response options as well as fill-in-the-blank options. The questionnaire was available in both English and simplified Chinese.

Data analysis consisted of descriptive statistics including means and percentages of demographic data for all participants. Frequencies of each survey response were also tabulated as percentages. Analysis using the $\chi^{2}$ test or Fisher's exact test, where applicable, evaluated any difference in responses between LB-experienced and LB-naive respondents. The $t$ test was used to determine whether the hypothesis that $>90 \%$ of patients would prefer FS to LB could be supported. Logistic regression analysis was used to evaluate any relationships between test preference and demographic characteristics, as well as
TABLE 1

Respondent demographics

\begin{tabular}{|c|c|c|c|c|}
\hline \multirow[b]{2}{*}{ Characteristic } & \multirow{2}{*}{$\begin{array}{c}\text { All } \\
\text { respondents, } n\end{array}$} & \multicolumn{2}{|c|}{ Liver biopsy } & \multirow[b]{2}{*}{$\mathbf{P}$} \\
\hline & & Naive & Experienced & \\
\hline $\begin{array}{l}\text { Age, years, } \\
\text { mean } \pm \text { SD }\end{array}$ & $53.5 \pm 12.1$ & $52.1 \pm 13.0$ & $55.1 \pm 11.0$ & 0.012 \\
\hline \multicolumn{5}{|l|}{ Sex } \\
\hline Male & $212(50.2)$ & $122(56.2)$ & $90(43.9)$ & 0.006 \\
\hline Female & $206(48.8)$ & 91 (41.9) & $115(56.1)$ & \\
\hline No response & $4(1.0)$ & $4(1.8)$ & $0(0)$ & \\
\hline \multicolumn{5}{|l|}{ Liver disease } \\
\hline Hepatitis C & $161(38.2)$ & $61(28.1)$ & $100(48.8)$ & $<0.0001$ \\
\hline Hepatitis B & $116(27.5)$ & $79(36.4)$ & 37 (18.1) & \\
\hline Don’t know & $48(11.4)$ & $32(14.8)$ & $16(7.8)$ & \\
\hline AlH & $37(8.8)$ & $7(3.2)$ & $30(14.6)$ & \\
\hline $\mathrm{NASH}$ & $27(6.4)$ & $21(9.7)$ & $6(2.9)$ & \\
\hline PBC & $18(4.3)$ & $7(3.2)$ & $11(5.4)$ & \\
\hline Not disclosed & $7(1.7)$ & $5(2.3)$ & $2(1)$ & \\
\hline No response & $4(1.0)$ & $3(1.4)$ & $1(0.5)$ & \\
\hline Hemochromatosis & $2(0.5)$ & $1(0.5)$ & $1(0.5)$ & \\
\hline Wilson disease & $1(0.2)$ & $0(0)$ & $1(0.5)$ & \\
\hline ALD & $1(0.2)$ & $1(0.5)$ & 0 & \\
\hline \multicolumn{5}{|l|}{ Ancestry } \\
\hline Caucasian & $228(54.7)$ & $93(43.9)$ & $135(65.9)$ & 0.001 \\
\hline East Asian & $131(31.4)$ & $82(38.7)$ & 49 (23.9) & \\
\hline South Asian & $25(6.0)$ & $16(7.6)$ & $9(4.4)$ & \\
\hline Other Asian & $13(3.1)$ & $9(4.3)$ & $4(2.0)$ & \\
\hline American Indian & $10(2.4)$ & $5(2.4)$ & $5(2.4)$ & \\
\hline Not disclosed & $5(1.2)$ & $3(1.4)$ & $2(1.0)$ & \\
\hline Black & $3(0.7)$ & $3(1.4)$ & $0(0)$ & \\
\hline $\begin{array}{l}\text { Hawaiian/Pacific } \\
\text { Islander }\end{array}$ & $2(0.5)$ & $1(0.5)$ & $1(0.5)$ & \\
\hline \multicolumn{5}{|c|}{ Annual household income, \$ } \\
\hline $0-24,999$ & $82(19.6)$ & $45(21.1)$ & $37(18.1)$ & 0.40 \\
\hline $25,000-49,999$ & $89(21.3)$ & $50(23.5)$ & $39(19.0)$ & \\
\hline $50,000-74,999$ & $67(16.0)$ & $34(16.0)$ & 33 (16.1) & \\
\hline$\geq 75,000$ & $110(26.3)$ & $55(25.8)$ & $55(26.8)$ & \\
\hline Not disclosed & $70(16.8)$ & $29(13.6)$ & $41(20.0)$ & \\
\hline
\end{tabular}

Data presented as $n(\%)$ unless otherwise indicated. AlH Autoimmune hepatitis; ALD Alcoholic liver disease; NASH Nonalcoholic steatohepatitis; PBC Primary biliary cirrhosis

willingness to pay and demographic characteristics. A two-tailed alpha level of significance of 0.05 was used for all statistical analyses.

\section{RESULTS}

The response rate in clinic was $99 \%(n=315)$ and via mail was $45 \%$ $(n=107)$, yielding an overall response rate of $76 \%$ (422 of 558). Of the 422 respondents, 205 were LB-experienced. Table 1 summarizes the demographic characteristics of respondents. The mean age of all respondents was 53.5 years and one-half $(50.2 \%)$ were male. The most common liver disease reported among respondents was hepatitis $\mathrm{C}$ (38.2\%), followed by hepatitis B (27.5\%) and "Don't know" (11.4\%). The majority of respondents were Caucasian (54.7\%) and East Asian (31.4\%). Annual household income was fairly evenly distributed among all respondents, with the greatest proportion of respondents $(26.3 \%)$ reporting an annual household income $\geq \$ 75,000$. In addition, a substantial proportion of respondents $(16.8 \%)$ preferred not to disclose their household income. There was a difference in sex and ancestry between the LB-naive and LB-experienced groups $(\mathrm{P}=0.006$ and $\mathrm{P}=0.001$, respectively). There was also a difference in age $(\mathrm{P}=0.012)$ and liver disease $(\mathrm{P}<0.0001)$ between the two groups. There was no difference in annual household income between the two groups $(\mathrm{P}=0.40)$. 
TABLE 2

Patient experience with transient elastography* versus liver biopsy

\begin{tabular}{|c|c|c|}
\hline & FibroScan $(n=422)$ & Liver biopsy $(n=205)$ \\
\hline \multicolumn{3}{|c|}{ Level of discomfort experienced during the test } \\
\hline None & $355(84.1)$ & $16(7.8)$ \\
\hline Mild & $61(14.5)$ & $55(26.8)$ \\
\hline Moderate & $6(1.4)$ & $69(33.7)$ \\
\hline Significant & $0(0)$ & $49(23.9)$ \\
\hline Severe & $0(0)$ & $15(7.3)$ \\
\hline Blank response & $0(0)$ & $1(0.5)$ \\
\hline \multicolumn{3}{|c|}{ Level of discomfort experienced after the test } \\
\hline None & $406(96.2)$ & $30(14.6)$ \\
\hline Mild & $13(3.1)$ & $60(29.3)$ \\
\hline Moderate & $2(0.5)$ & $63(30.7)$ \\
\hline Significant & $1(0.2)$ & $38(18.5)$ \\
\hline Severe & $0(0)$ & $13(6.3)$ \\
\hline Blank response & $0(0)$ & $1(0.5)$ \\
\hline \multicolumn{3}{|c|}{ Level of anxiety experienced after test explanation before the test } \\
\hline None & $330(78.2)$ & $26(12.7)$ \\
\hline Mild & $73(17.3)$ & $40(19.5)$ \\
\hline Moderate & $17(4.0)$ & $78(38.1)$ \\
\hline Significant & $1(0.2)$ & $52(25.4)$ \\
\hline Severe & $0(0)$ & $8(3.9)$ \\
\hline Blank response & $1(0.2)$ & $1(0.5)$ \\
\hline \multicolumn{3}{|c|}{ The test was too long } \\
\hline No & $410(97.2)$ & $99(48.3)$ \\
\hline Somewhat & $11(2.6)$ & $65(31.7)$ \\
\hline Yes & $0(0)$ & $39(19.0)$ \\
\hline Blank response & $1(0.2)$ & $2(1.0)$ \\
\hline \multicolumn{3}{|c|}{ There was a long wait to receive the test results } \\
\hline No & $403(95.5)$ & $62(30.2)$ \\
\hline Somewhat & $13(3.1)$ & $86(42.0)$ \\
\hline Yes & $1(0.2)$ & $54(26.3)$ \\
\hline Blank response & $5(1.2)$ & $3(1.5)$ \\
\hline \multicolumn{3}{|c|}{ Time taken off work to undergo the test, $\mathrm{h}$} \\
\hline$<2$ & $128(30.3)$ & $9(4.4)$ \\
\hline $2-4$ & $53(12.6)$ & $15(7.3)$ \\
\hline $4-6$ & $11(2.6)$ & $18(8.8)$ \\
\hline$>6$ & $19(4.5)$ & $61(29.8)$ \\
\hline Not applicable & 209 (49.5) & $99(48.3)$ \\
\hline Blank response & $2(0.5)$ & $3(1.4)$ \\
\hline
\end{tabular}

Data presented as $n$ (\%). *FibroScan, Echosens, France

Regarding patient experience, the majority (84.1\%) of all respondents experienced no discomfort during the performance of FS. In comparison, few of the LB-experienced respondents (7.8\%) felt no discomfort during the LB, while the majority (33.7\%) experienced moderate discomfort. The majority $(96.2 \%)$ of all respondents also reported experiencing no discomfort after FS, compared with only $14.6 \%$ of LB-experienced respondents feeling no discomfort after LB. Specifically, discomfort after LB was reported to be mild $(29.3 \%)$ to moderate $(30.7 \%)$ by the majority of LB-experienced respondents. The level of anxiety experienced after the FS explanation, but before the test, was reported to be 'none' by $78.2 \%$ of all respondents, compared with only $12.7 \%$ of LB-experienced respondents after LB explanation. The perceived duration of FS was not considered to be too long by $97.2 \%$ of respondents, and the perceived duration of LB was not considered to be too long by $48.3 \%$ of LB-experienced respondents. The majority $(95.5 \%)$ of all respondents reported that the wait time was not too long for the FS result, while $30.2 \%$ of LB-experienced respondents reported that the wait time was not too long for the LB result. In terms of the amount of time taken off work for the tests, 30.3\% reported taking $<2 \mathrm{~h}$ off for FS while $4.5 \%$ reported taking $>6$ h off for FS. Only $4.4 \%$ of
TABLE 3

Survey responses regarding transient elastography* experience for liver biopsy-naive versus liver biopsy-experienced respondents

\begin{tabular}{|c|c|c|c|c|}
\hline \multirow{2}{*}{$\begin{array}{l}\text { Survey } \\
\text { responses }\end{array}$} & \multicolumn{2}{|c|}{ Liver biopsy } & \multirow[b]{2}{*}{ Total } & \multirow[b]{2}{*}{$\mathbf{P}$} \\
\hline & Naive & Experienced & & \\
\hline \multicolumn{5}{|c|}{ Level of discomfort experienced during FibroScan* } \\
\hline None & $190(87.6)$ & $165(80.5)$ & $355(84.1)$ & 0.106 \\
\hline Mild & $24(11.1)$ & $37(18.1)$ & $61(14.5)$ & \\
\hline Moderate & $3(1.4)$ & $3(1.5)$ & $6(1.4)$ & \\
\hline Significant & $0(0)$ & $0(0)$ & $0(0)$ & \\
\hline Severe & $0(0)$ & $0(0)$ & $0(0)$ & \\
\hline \multicolumn{5}{|c|}{ Level of discomfort experienced after FibroScan } \\
\hline None & $212(97.7)$ & $194(94.6)$ & $406(96.2)$ & 0.226 \\
\hline Mild & $4(1.8)$ & $9(4.4)$ & $13(3.1)$ & \\
\hline Moderate & $1(0.5)$ & $1(0.5)$ & $2(0.5)$ & \\
\hline Significant & $0(0)$ & $1(0.5)$ & $1(0.2)$ & \\
\hline Severe & $0(0)$ & $0(0)$ & $0(0)$ & \\
\hline
\end{tabular}

Level of anxiety experienced after FibroScan explanation before the test

$\begin{array}{lcccc}\text { None } & 172(79.6) & 158(77.1) & 330(78.4) & 0.778 \\ \text { Mild } & 35(16.2) & 38(18.5) & 73(17.3) & \\ \text { Moderate } & 9(4.2) & 8(3.9) & 17(4.0) & \\ \text { Significant } & 0(0) & 1(0.5) & 1(0.2) \\ \text { Severe } & 0(0) & 0(0) & 0(0)\end{array}$

The FibroScan was too long

$\begin{array}{lcccc}\text { No } & 213(98.2) & 197(96.6) & 410(97.4) & 0.369 \\ \text { Somewhat } & 4(1.8) & 7(3.4) & 11(2.6) & \\ \text { Yes } & 0(0) & 0(0) & 0(0) & \end{array}$

There was a long wait to receive the FibroScan results

\begin{tabular}{lcccc} 
No & $208(97.2)$ & $195(96.1)$ & $403(96.6)$ & 0.677 \\
Somewhat & $6(2.8)$ & $7(3.5)$ & $13 .(3.1)$ & \\
Yes & $0(0)$ & $1(0.5)$ & $1(0.2)$ & \\
\hline
\end{tabular}

Data presented as $n(\%)$ unless otherwise indicated. ${ }^{*}$ FibroScan, Echosens, France

respondents reported taking $<2 \mathrm{~h}$ off work for $\mathrm{LB}$ while $29.8 \%$ reported taking $>6$ h off. Table 2 presents a summary of the responses. There was no significant difference in the responses provided to questions relating to FS experience among LB-naive respondents when compared with LB-experienced respondents (Table 3).

In terms of patient preference, the majority of respondents preferred FS to LB if both were available at no charge (95.4\% versus $4.6 \%$, respectively) (Figure 1). The results were similar among LB-experienced patients, with $95.1 \%$ preferring $\mathrm{FS}$ and $4.9 \%$ preferring LB. Of all respondents, $75.3 \%$ were willing to self-pay for FS even if LB was reimbursed by the province (Figure 2). The results were similar among LB-experienced patients (76.1\%). Among all individuals who were willing to pay, the amount they were willing to pay varied without any particular amount being significantly preferred (Figure 3). However, the majority (26.3\%) of respondents were willing to pay $\$ 25$ to $\$ 49$ for FS.

Logistic regression analysis was used to evaluate relationships between test preference (FS or LB) and demographic characteristics, including age, sex, previous biopsy experience, household income, liver disease and ancestry, and also to evaluate relationships between willingness to pay (yes or no) and the same demographic characteristic. There were no significant associations between test preference or willingness to pay and the demographic variables tested. However, the only variable significantly associated with lower odds of FS preference was unknown etiology of liver disease (OR 0.20 [95\% CI 0.07 to 0.53]; $\mathrm{P}=0.001)$.

\section{DISCUSSION}

The present study was the first to evaluate preference for FS versus LB among patients. It demonstrates a greater preference for FS regardless of previous LB experience. In particular, patients tend to feel more 


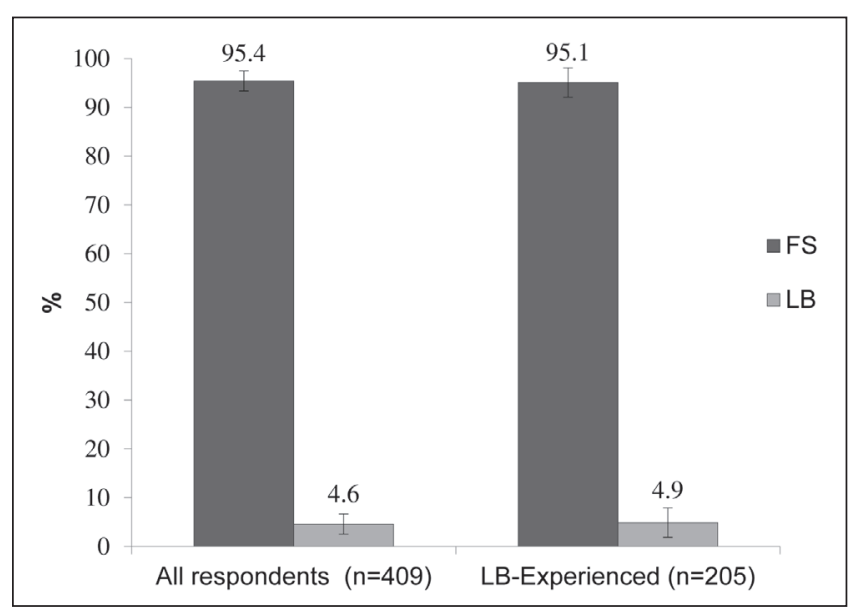

Figure 1) Patient preference according to all respondents and liver biopsy (LB)-experienced respondents. FS FibroScan (Echosens, France)

comfortable with FS than with LB, reporting little to no discomfort during and after the test, and less anxiety before the test. They also tended to associate less time with FS than with LB, reporting shorter test duration, shorter wait time for results and a reduced amount of time off work.

Our survey further reveals that an overwhelming majority (95.4\%) of patients prefer FS to LB if both tests are available at no cost to them. This result did not change when only LB-experienced respondents were considered $(95.1 \%)$, further establishing the clear preference for FS to LB. Seventy-five percent of patients reported being willing to self-pay to undergo FS if only LB was publicly funded. Again, previous LB experience did not affect the response rate. The reason for unwillingness to pay for FS was not explored in the present study. It was speculated that some of these individuals may be unwilling to pay based on principle due to the fact that provision of health care services in Canada is predominantly publicly funded. The results, nevertheless, suggest that the majority of patients prefer FS and would be willing to pay to undergo the test.

Interestingly, of the respondents who were willing to pay for FS, the majority $(26.3 \%)$ report they would pay between $\$ 25$ and $\$ 49$. The response rates for other amount categories were fairly close, however, with the second highest percentage of respondents (19.5\%) willing to pay $>\$ 100$. These results do not suggest that a significant proportion of patients would pay exorbitant amounts for FS, nor do they suggest that they would pay negligible amounts. They do, however, suggest that the amount an individual is willing to pay is highly variable and may depend on a host of factors not explored in the present study.

Surprisingly, patients who reported having an unknown diagnosis of liver disease preferred LB (OR for FS preference 0.2 [95\% CI 0.07 to $0.53]$ ). This suggests that $L B$ could still provide valuable information for this subset of patients, and is also consistent with the fact that LB is able to diagnose both liver disease and liver fibrosis, while FS can only diagnose liver fibrosis. Comparably, a survey of Canadian physicians discovered that autoimmune/cholestatic liver disease was the only liver disease category that was not reported to be associated with a reduction in LB practice or a tendency for higher use of noninvasive methods for assessing liver fibrosis (16). These findings may have significant implications for the use of LB in future clinical practice. For instance, LB may no longer be necessary for individuals with liver disease that can be diagnosed through serological tests or other lessinvasive means. Instead, it may have greater utilization among individuals with liver disease of unknown etiology due to its ability to provide differential diagnoses. Furthermore, for individuals who require differential diagnosis but are hesitant to undergo LB, fibrosis assessment via FS may help guide the physician and patient's decision as to whether (or when) definitive diagnosis via LB is necessary.

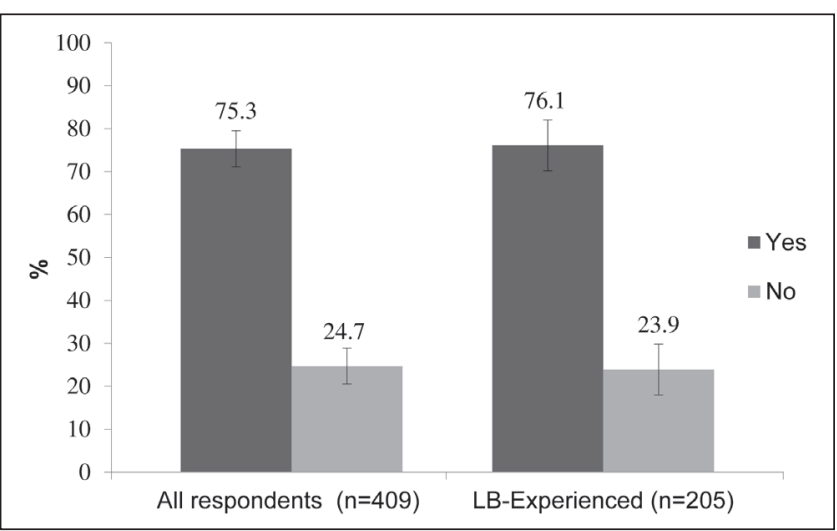

Figure 2) Willingness to pay for transient elastography (FibroScan, Echosens, France) according to all respondents and liver biopsy (LB)experienced respondents

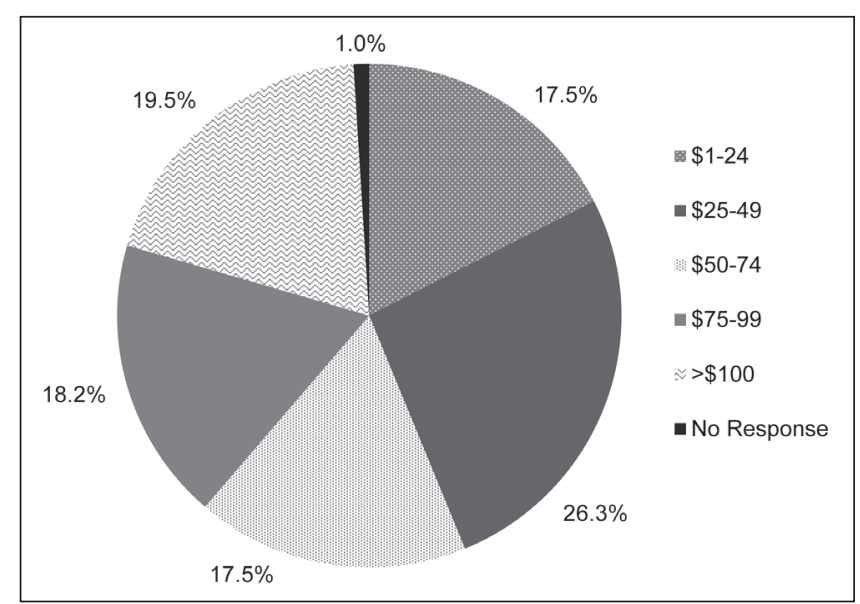

Figure 3) Amount willing to pay for transient elastography (FibroScan, Echosens, France) among all respondents

Our study had several limitations. While the overall response rate $(76 \%)$ was satisfactory, the response rate among participants being reached through mail was relatively low $(45 \%)$. Although other studies of similar nature also obtained similar response rates (16), the low response via mail limited the data we could have obtained from the unique perspective of individuals who had the experience of both FS and LB. Additionally, the survey was conducted from one site in Vancouver, limiting the representation of other patient populations in British Columbia. Another disadvantage of conducting the survey at a single site is that the processes at the site may be distinct from other clinics. For instance, it is standard at the site for a patient to undergo FS and review their result with the physician on the same day. Thus, we acknowledge that not all sites operate in such a fashion. Recall bias is another limitation of the study because the survey relied on patient's self-assessed experience of both tests. This is particularly true for selfassessed reports on LB experience because LB could have been performed quite a few years before FS.

\section{CONCLUSION}

The present study evaluated preference for FS versus LB among patients. Because patients are key stakeholders in the current efforts being made toward implementing a reimbursement policy for FS in British Coumbia, knowledge of their preference is invaluable. Our findings demonstrate that the majority of patients preferred FS to $\mathrm{LB}$, associating FS with increased comfort and speed compared with LB. This preference was further demonstrated by the willingness of the majority of patients to self-pay for FS if only LB were publicly funded. Despite this preference for FS, lack of convenient access to 
FS among Canadian physicians, as demonstrated in previous studies, and varying costs of obtaining FS technology continue to be limiting factors for FS access among patients in British Columbia. Thus, these findings emphasize the need for provincial funding for FS to minimize regional variation regarding access to and availability of FS, as well as to ensure consistent monitoring of liver disease progression and management of chronic liver disease throughout the province. Furthermore, this could minimize the need for LB among a significant proportion of the population who do not wish to undergo, or are ineligible for, an invasive procedure. It is noted, however, that LB remained the procedure of choice for individuals with an unknown diagnosis.

DISCLOSURES AND ACKNOWLEDGEMENTS: None of the authors has a competing interest with regard to this work. The authors sincerely thank Mr and Mrs Arran and Ratana Stephens and Nature's Path Organic Foods for their generous support that facilitated the acquisition of our Fibroscan unit and ongoing liver disease research.

\section{REFERENCES}

1. Cadranel JF, Rufat P, Degos F. Practices of liver biopsy in France: Results of a prospective nationwide survey. For the Group of Epidemiology of the French Association for the Study of the Liver (AFEF). Hepatology 2000;32:477-81.

2. Firpi RJ, Soldevila-Pico C, Abdelmalek MF, Morelli G, Judah J, Nelson DR. Short recovery time after percutaneous liver biopsy: Should we change our current practices? Clin Gastroenterol Hepatol 2005;3:926-9.

3. Myers RP, Fong A, Shaheen AA. Utilization rates, complications and costs of percutaneous liver biopsy: A population-based study including 4275 biopsies. Liver Int 2008;28:705-12.

4. Robert M, Sofair AN, Thomas A, et al. A comparison of hepatopathologists' and community pathologists' review of liver biopsy specimens from patients with hepatitis C. Clin Gastroenterol Hepatol 2009; 7:335-8.
5. Hølund B, Poulsen H, Schlichting P. Reproducibility of liver biopsy diagnosis in relation to the size of the specimen. Scand J Gastroenterol 1980;15:329-35.

6. Regev A, Berho M, Jeffers LJ, et al. Sampling error and intraobserver variation in liver biopsy in patients with chronic HCV infection. Am J Gastroenterol 2002;97:2614-8.

7. de Lédinghen V, Vergniol J. Transient elastography (FibroScan). Gastroenterol Clin Biol 2008;32:58-67.

8. Sandrin L, Fourquet B, Hasquenoph J, et al. Transient elastography: A new noninvasive method for assessment of hepatic fibrosis. Ultrasound Med Biol 2003;29:1705-13.

9. Shaheen A. FibroTest and FibroScan for the prediction of hepatitis C-related fibrosis: A systematic review of diagnostic test accuracy. Am J Gastroenterol 2007;102:2589-600.

10. Castéra L, Vergniol J, Foucher J, et al. Prospective comparison of transient elastography, Fibrotest, APRI, and liver biopsy for the assessment of fibrosis in chronic hepatitis C. Gastroenterology 2005;128:343-50.

11. Friedrich-Rust M, Ong M, Martens S, et al. Performance of transient elastography for the staging of liver fibrosis: A meta-analysis. Gastroenterology 2008;134:960-74.

12. Foucher J, Castéra L, Bernard P, et al. Prevalence and factors associated with failure of liver stiffness measurement using FibroScan in a prospective study of 2114 examinations. Eur J Gastroenterol Hepatol 2006;18:411-2.

13. Wong GL, Wong VW, Chim AM, et al. Factors associated with unreliable liver stiffness measurement and its failure with transient elastography in the Chinese population. J Gastroenterol Hepatol 2011;26:300-5.

14. Castéra L, Foucher J, Bernard P, et al. Pitfalls of liver stiffness measurement: A 5-year prospective study of 13,369 examinations. Hepatology 2010;51:828-35.

15. Aljawad M, Yoshida EM, Uhanova J, Marotta P, Chandok N. Percutaneous liver biopsy practice patterns among Canadian hepatologists. Can J Gastroenterol 2013;27:e31-4.

16. Sebastiani G, Ghali P, Wong P, Klein MB, Deschenes M, Myers RP. Physicians' practices for diagnosing liver fibrosis in chronic liver diseases: A nationwide, Canadian survey. Can J Gastroenterol Hepatol 2014;28:23-30. 


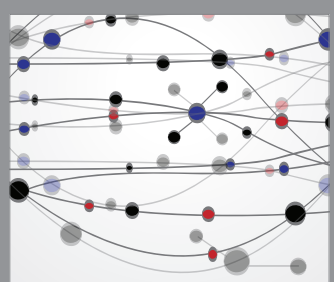

The Scientific World Journal
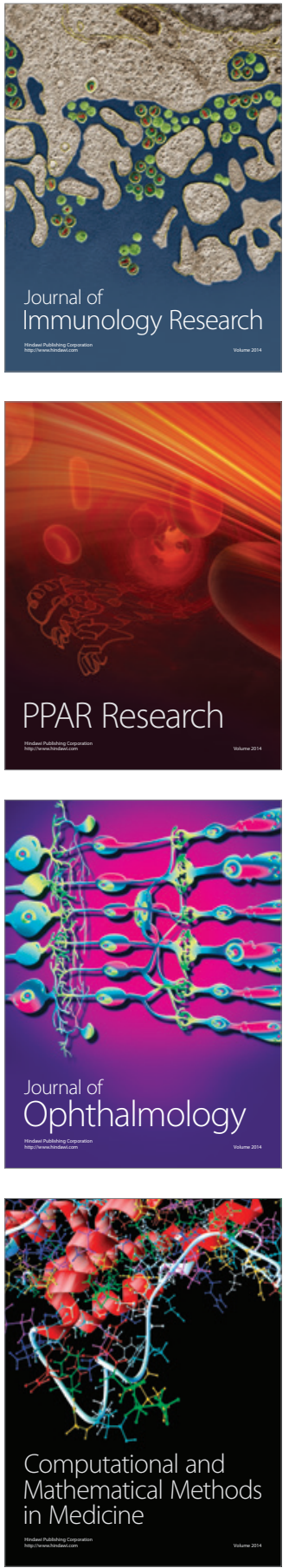

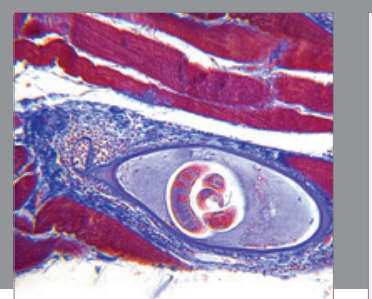

Gastroenterology Research and Practice

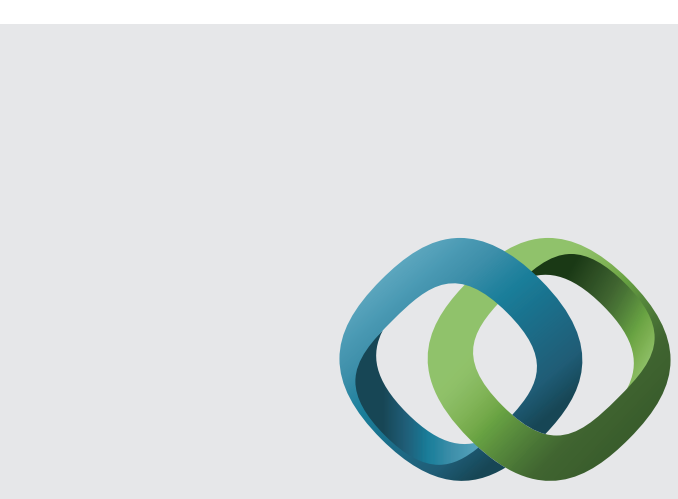

\section{Hindawi}

Submit your manuscripts at

http://www.hindawi.com
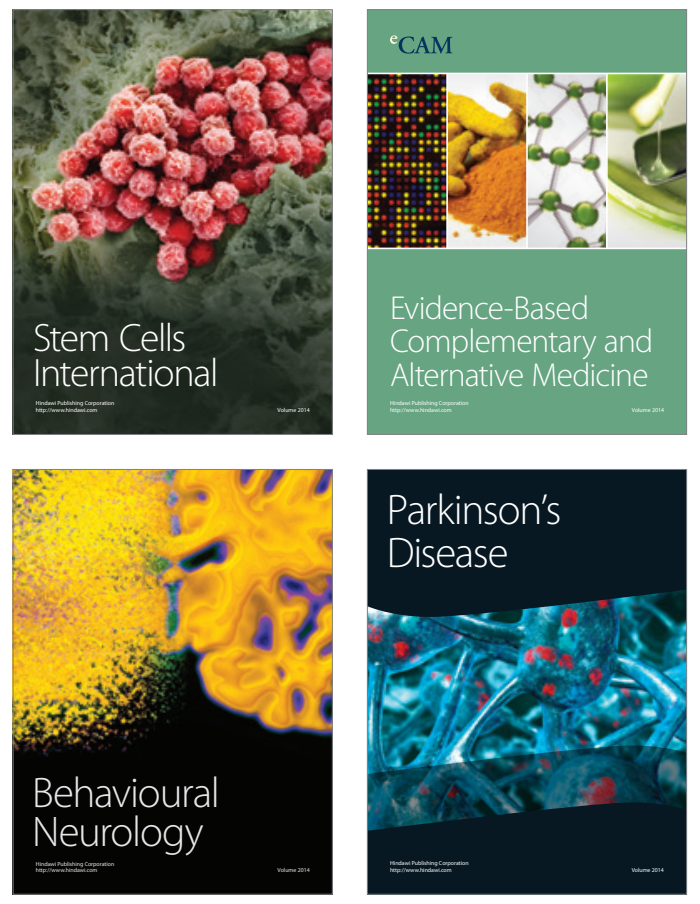
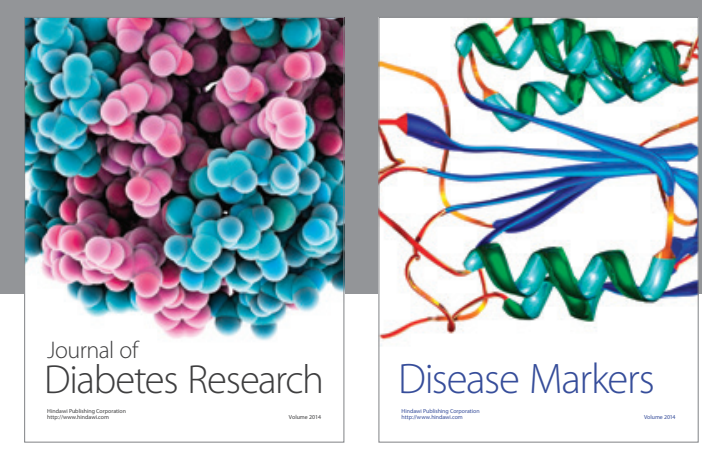

Disease Markers
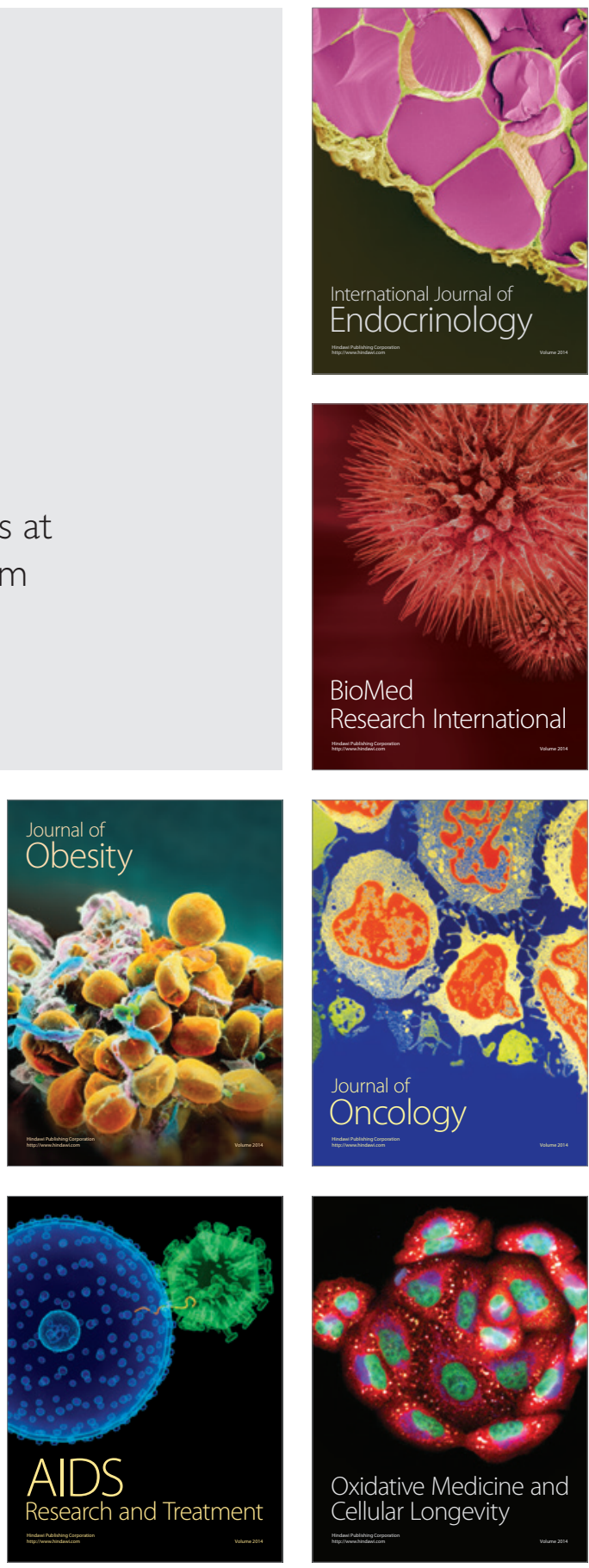